\title{
Genetic control of resistance to salmonellosis and to Salmonella carrier-state in fowl: a review
}

\author{
Fanny Calenge ${ }^{* 1}$, Pete Kaiser ${ }^{2,4}$, Alain Vignal ${ }^{3}$ and Catherine Beaumont ${ }^{1}$
}

\begin{abstract}
Salmonellosis is a frequent disease in poultry stocks, caused by several serotypes of the bacterial species Salmonella enterica and sometimes transmitted to humans through the consumption of contaminated meat or eggs. Symptomfree carriers of the bacteria contribute greatly to the propagation of the disease in poultry stocks. So far, several candidate genes and quantitative trait loci (QTL) for resistance to carrier state or to acute disease have been identified using artificial infection of S. enterica serovar Enteritidis or S. enterica serovar Typhimurium strains in diverse genetic backgrounds, with several different infection procedures and phenotypic assessment protocols. This diversity in experimental conditions has led to a complex sum of results, but allows a more complete description of the disease. Comparisons among studies show that genes controlling resistance to Salmonella differ according to the chicken line studied, the trait assessed and the chicken's age. The loci identified are located on 25 of the 38 chicken autosomal chromosomes. Some of these loci are clustered in several genomic regions, indicating the possibility of a common genetic control for different models. In particular, the genomic regions carrying the candidate genes TLR4 and SLC11AT, the Major Histocompatibility Complex (MHC) and the QTL SAL1 are interesting for more in-depth studies. This article reviews the main Salmonella infection models and chicken lines studied under a historical perspective and then the candidate genes and QTL identified so far.
\end{abstract}

\section{Background}

Salmonellosis is a zoonotic disease caused by the Gramnegative enteric bacterium Salmonella. More than 2500 serotypes have been described, mostly belonging to the species S. enterica [1]. Some Salmonella serotypes can infect a broad range of domestic animals including poultry, sheep, cattle and pigs and cause symptoms of varying severity ranging from mild gastro-enteritis to death. Some of these serotypes, such as $S$. Typhimurium and $S$. Enteritidis, can infect humans. Other serotypes are hostspecific, infecting a single species and generally causing severe, typhoid-like symptoms sometimes leading to death (for instance, S. Gallinarum and S. Pullorum in poultry). These serotypes can be responsible for disease outbreaks leading to severe economic losses.

Prophylactic measures, vaccination and use of antibiotics are insufficient to eradicate salmonellosis in poultry stocks, whatever the serotype involved. In this context, selection of more resistant chickens can be considered as an alternative solution to decrease occurrence of the dis-

* Correspondence: Fanny.Calenge@tours.inra.fr

1 INRA, UR83 Unité de Recherches Avicoles (URA), 37380 Nouzilly, France Full list of author information is available at the end of the article ease. The first selection experiments at the beginning of the $20^{\text {th }}$ century aimed to decrease disease occurrence in poultry production systems, which was mainly caused by $S$. Pullorum and $S$. Gallinarum. As food safety became an important concern and these host-specific serotypes were better controlled, the interest of researchers and breeders extended towards decreasing food contamination, mainly due to the serotypes Enteritidis and Typhimurium. S. Enteritidis alone, which infects the eggs of contaminated hens, is responsible for one third of the human food poisoning cases in France [2] and of about $15 \%$ in the UK in 2007 http://www.defra.gov.uk/foodfarm/farmanimal/diseases/atoz/zoonoses/reports.htm. It does not cause severe symptoms in poultry, but the eggs and meat of infected animals can become a reservoir of infection for the human consumer. In particular, asymptomatic carriers have a major role in Salmonella propagation in poultry and hence in food contamination, since they cannot be easily identified and isolated. This is the reason why today resistance to carrier-state ability, and not only to general salmonellosis resistance, is taken into account by some breeders and researchers. Simulation studies demonstrate the usefulness of rearing animals 
more resistant to carrier state in the prevention of disease propagation in poultry, in synergy with vaccination [3].

Experiments for the selection of genetically resistant animals can be traced back as early as the 1930's [4,5] and the first step was the demonstration that distinct disease resistances or susceptibilities exist between different lines or breeds of chicken. The second step consisted in evaluating the heritability of disease resistance-related traits, which confirmed that the observed variability among lines had a genetic origin [6-8]. Next, genomic regions responsible for the observed genetic variability were identified, which provided a better understanding of the mechanisms involved in resistance and should theoretically lead to marker-assisted selection (MAS). MAS can potentially accelerate the selection process, and prevent infection of animals. To date, two different approaches have been used successfully to unravel the genetic control of disease resistance variability, i.e. (1) candidate gene approaches with a priori knowledge of the genes potentially involved (for instance, [9-11]) and (2) quantitative approaches through quantitative trait locus (QTL) analyses, which have been conducted since the development of molecular markers in the 1990's [12-15]. A final step towards obtaining more resistant animals is selection itself, with or without the contribution of molecular markers. The feasibility of selection for increased resistance to $S$. Enteritidis carrier-state has been demonstrated [16]. Nevertheless, molecular markers still have to be included in the selection process, in order to take advantage of the recent knowledge acquired on genetic resistance mechanisms.

In this article, we review the literature on studies aimed at identifying the genes responsible for variable resistance to salmonellosis in chicken. The article is organised as follows: (1) the different Salmonella infection models, (2) the genetic resources used, (3) the candidate gene approaches, (4) the QTL analyses conducted and (5) the co-localisations occurring between candidate genes and QTL.

\section{The Salmonella infection models: a historical perspective} Many different Salmonella infection protocols are described in the literature. Here, we focus on the protocols that have been used for genetic studies. Many factors have to be taken into account to assess Salmonella resistance i.e. infectious doses, Salmonella serotypes and strains, route and age of infection, delay between infection and phenotypic observations, and the animal rearing conditions. In addition, different parameters can be measured: survival rate, lethal dose leading to $50 \%$ of dead animals (LD50), internal organ contamination, presence/ absence of Salmonella, Salmonella count, etc. The main infection models used to identify genes for resistance to Salmonella are summarized in Table 1.
At the beginning of the $20^{\text {th }}$ century, the breeder's main objective was to reduce mortality in industrial poultry stocks. For practical reasons, Salmonella resistance assessment was carried out on young chicks (1 day to 2 weeks). Chicks are more susceptible to salmonellosis than adults, so that discrimination among animals was evaluated via their survival rates. Chicks were infected with a high dose of the serotypes that were known to cause the most severe symptoms in infected chicken, i.e. S. Pullorum, S. Gallinarum and $S$. Typhimurium [4,5,17-20]. Some studies also reported infection of hens at peak of lay [21], because the possibility of vertical transmission of bacteria to eggs was already a concern. Different infection routes were used according to the study: oral [19-21], intraperitoneal [4], or subcutaneous [17]. With the improvement of alternative disease control practices, such as chemotherapy, competitive exclusion, prophylactic measures, use of antibiotics and vaccination, disease outbreaks in poultry stocks were reduced and the interest in selection for Salmonella resistance decreased.

In the 1980s, the number of human food poisoning outbreaks increased, mainly due to $S$. Enteritidis, which renewed the interest to select more resistant animals. Several studies aimed at comparing the effects of different serotypes on mortality rates, and of the route of inoculation (intramuscular or oral) were carried out on dayold chicks [22-24]. A few studies assessed the carrier state of chickens infected with $S$. Enteritidis, since symptomless carriers are the main cause of disease propagation in poultry. In such studies, the persistence of bacteria in infected chickens has to be assessed several weeks postinfection. Guillot et al. [25] infected day-old chicks with high doses (orally or intra-muscularly) but followed the persistence of bacteria in several internal organs, in addition to measuring mortality. Duchet-Suchaux et al. $[26,27]$ developed a model in which one week-old chicks were orally infected with a smaller dose of bacteria, thus preventing mortality and disease symptoms, in order to observe the persistence of bacteria in different organs several weeks after infection. The carrier-state in adult chickens has been less well studied. Protais et al. [28] and Lindell et al. [29] orally infected adult hens at peak of lay and followed the persistence of bacteria in different organs.

In the above studies, Salmonella resistance was assessed by observing survival rates or quantities or presence/absence of bacteria in different organs. In more recent studies, indirect, linked parameters have been used to characterise Salmonella resistance: innate or adaptive immunity-related traits [30-32], antibody response after a $S$. Enteritidis vaccine $[12,15]$, or gene expression by genome-wide, microarray analyses [33-35] or more targeted studies focusing on one or several genes [36-41]. Observation of these traits contributes to a better 
Table 1: Infection models used in published studies of the genetic control of resistance to Salmonella in fowl

\begin{tabular}{|c|c|c|c|c|c|c|c|}
\hline Locus type $^{1}$ & Infection route & Age $^{2}$ & $\begin{array}{l}\operatorname{Time}^{3} \\
\text { (pi) }\end{array}$ & Trait $^{4}$ & Cross type & Parental lines $^{5}$ & Ref6 $^{6}$ \\
\hline MSAT & subcuta-neaous & $10 \mathrm{~d}$ & $10 \mathrm{~d}$ & $A B R$ to $S E$ vaccine & $\mathrm{F} 2+\mathrm{BC}$ & (low $\times$ high) $A B R$ divergent inbred lines & {$[15]$} \\
\hline $\begin{array}{l}\text { MSAT } \\
\text { CG }\end{array}$ & subcuta-neaous & $10 \mathrm{~d}$ & $21 d$ & $A B R$ to $S E$ vaccine & $\mathrm{F} 1$ & $\begin{array}{l}\text { Broiler outbred male } \times 3 \text { inbred lines ( } 2 \text { MHC- } \\
\text { congenic WL + Fay) }\end{array}$ & $\begin{array}{l}{[12]} \\
{[64]}\end{array}$ \\
\hline QTL & oral & $1 \mathrm{w}$ & $4 / 5 w$ & CSWB counts/caecal load & $\mathrm{F} 2$ & $\left(N \times \sigma_{1}\right) \times\left(N \times \sigma_{1}\right)$ layer inbred lines & {$[14]$} \\
\hline QTL & oral & $6 w$ & $2 w$ & CSWB counts/caecal load & $\mathrm{BC}$ & $\left(N \times \sigma_{1}\right) \times \sigma_{1}$ layer inbred lines & [14] \\
\hline QTL & oral & $2 w$ & $5 d$ & splenic load & $\mathrm{BC}$ & $\left(6_{1} \times 151\right) \times 6_{1}$ layer inbred lines & [13] \\
\hline CG & subcuta-neaous & $10 \mathrm{~d}$ & $11 \mathrm{~d}$ & $A B R$ to $S E$ vaccine & $\mathrm{F} 2$ & $($ Fay $\times W L) \times($ Fay $\times W L)$ & [66] \\
\hline CG & intra-oesophageal & $10 \mathrm{~d}$ & $21 \mathrm{~d}$ & $A B R$ to $S E$ vaccine & $\mathrm{F} 1$ & $\begin{array}{l}\text { Broiler outbred male } \times 3 \text { inbred lines ( } 2 \text { MHC- } \\
\text { congenic WL }+ \text { Fay) }\end{array}$ & {$[61-63]$} \\
\hline CG & intra-oesophageal & $1 \mathrm{~d}$ & $7 / 8 d$ & spleen and caecal loads & F8 & AlL $($ Broiler $\times$ Fay $) \times$ AlL (Broiler $\times$ inbred WL) & [59] \\
\hline CG & intravenous & $13 w$ & $3 d$ & spleen and liver loads & $\mathrm{F} 1$ & Egg-type commercial crosses & [7] \\
\hline CG & oral & peak of lay & $4 w$ & spleen load; number of contaminated organs & $\mathrm{F} 1$ & Egg-type commercial crosses & [9] \\
\hline CG & intra-muscular & $1 \mathrm{~d}$ & death or $2 \mathrm{w}$ & survival rate & $\mathrm{BC}$ & $(W \mid x C) \times C$ & {$[10]$} \\
\hline CG & intra-muscular & $1 \mathrm{~d}$ & death or $2 \mathrm{w}$ & survival rate & Fo & Inbred WL lines & [54] \\
\hline CG & intra-oesophageal & $1 \mathrm{~d}$ & $6 / 7 d$ & caecal and spleen loads & $\mathrm{F} 1$ & $\begin{array}{l}\text { Broiler outbred male } \times 3 \text { inbred lines }(2 \text { MHC- } \\
\text { congenic WL }+ \text { Fay) }\end{array}$ & {$[55,61-63,78]$} \\
\hline CG & intra-oesophageal & $1 \mathrm{~d}$ & $6 d$ & caecal and spleen loads & F8 & (Broiler $\times$ Fay) $\times$ AIL (Broiler $\times$ inbred WL) & {$[60]$} \\
\hline CG & oral & $3 w$ & $7 d$ & caecal load & Fo & 5 groups of meat type chicken & [11] \\
\hline
\end{tabular}

ICG: candidate gene, MSAT: microsatellite

2 Animal age at infection or injection; d: day; w: week

${ }^{3}$ Assessment time post inoculation (pi)

${ }^{4} \mathrm{ABR}$ : antibody response; CSW: cloacal swab; SE: Salmonella Enteritidis

${ }^{5}$ AlL: advanced intercross lines; Fay: Fayoumi; WL: White Leghorn

${ }^{6}$ Reference 
understanding of the immunological and transcriptional mechanisms involved in resistance differences between lines.

\section{Comparing Salmonella resistance levels between chicken lines}

The first step towards the identification of resistance genes is to choose and mate parental lines that differ in Salmonella resistance levels. Phenotypic variation is very high in poultry. For research purposes, inbred lines derived from selected breeds are the material of choice because of their higher rate of homozygosity and their relationship to actual commercial breeds. The first published studies at the beginning of the $20^{\text {th }}$ century reported comparisons of different layer lines, i.e. mainly White Leghorn and Rhode Island Red lines [4,5,17-21]. Most of these studies mention the greater resistance of the Rhode Island Red compared to the White Leghorn lines. The following studies used inbred or partially inbred lines generated from commercial layer or broiler lines. Mortalities after $S$. Typhimurium or $S$. Enteritidis infection of the inbred lines N, C, 15I, Wl, $6_{1}, 7_{2}$ and 0 , all derived from White Leghorn layer lines, have been compared [22-24,42]. Lines $C, 7_{2}$ and $15 \mathrm{I}$ were always more susceptible, whereas lines $\mathrm{N}, 6_{1}$ and Wl were always more resistant to infection. This line ranking was identical whatever the serotype used. Mortality and persistence of bacteria in internal organs were compared in the experimental White Leghorn inbred lines B13 and Y11, in the meat-type experimental line Y11, and in a commercial line (L2) [25-27]. Some studies used lines which were especially selected to study disease resistance: for instance, divergent lines for low/high antibody response [25].

The effects of genetic differences in resistance to Salmonella can be investigated by studying traits related to the immune response on different chicken lines. Heterophil functionality has been measured in several commercial lines of birds differing in their resistance to $S$. Enteritidis [43-45]. Crop immune response has been measured in eight commercial layer hens and White Leghorn chickens [32]. Some studies report genetic differences for the antibody response to $S$. Enteritidis $[15,46,47]$. Similarly, many studies report gene expression differences between different chicken lines after artificial infection, identified by genome-wide, microarray analyses [33-35] or more targeted studies focusing on one or several genes [36-41]. Other studies used lines selected for other traits (such as growth rate or feed conversion efficiency $[33,48]$ ), which makes it possible to investigate the interaction between the main trait under study and Salmonella resistance.

\section{Candidate gene approaches}

A candidate gene approach requires a priori knowledge of the genes potentially involved in Salmonella resistance. The first candidate gene tested in chicken was chosen on the basis of genetic studies carried out in mice infected by $S$. Typhimurium. This gene, NRAMP1 (natural resistance-associated macrophage protein, now SLC11A1), has been identified on mouse chromosome 1 , under the name Ity (Immunity to Typhimurium), after mice strains were classified into two categories: resistant vs. susceptible, as reviewed in [49]. The identity of Ity with two other genes, Bcg and Lsh, involved in resistance to, respectively, Mycobacterium bovis and Leishmania donovani, was demonstrated after the positional cloning of a unique gene, NRAMP1 [50]. NRAMP1 has since been described as a member of a solute carrier gene family and hence renamed SLC11A1. Physiological and functional studies support the role of SLC11A1 in the control of the intracellular replication of parasites in phagosomes. A homologue of NRAMP1 has been mapped on chicken chromosome 7 [51,52] and cloned subsequently [53]. Another major gene, TLR4 (Toll-like receptor 4), previously named Lps, belongs to a family of innate immune system receptors (Toll-like receptors) and is involved in the recognition of LPS (lipo-polysaccharide) from Gramnegative bacteria. Lps was mapped to mouse chromosome 4 after analysis of mouse strain $\mathrm{C} 3 \mathrm{H} / \mathrm{HeJ}$ which has both a hypo-responsiveness to LPS motifs and a higher susceptibility to $S$. Typhimurium. Positional cloning of Lps led to the identification of TLR4 as a positional candidate. The chicken homologue of TLR4 has been mapped to micro-chromosome 17 and cloned [54].

Several studies have attempted to determine whether SLC11A1 and TLR4 are involved in resistance variation to $S$. Typhimurium and $S$. Enteritidis. The survival rate of young chicks derived from a backcross between lines W1 and $C$ and infected intra-muscularly one day post-hatch with S. Typhimurium was linked to SLC11A1 and TLR4, which, together, explained up to $33 \%$ of the differential resistance to infection $[10,54]$. This effect was observed only during the first seven days post-infection. An effect of SLC11A1 on the early stages of systemic Salmonella infection using day-old chicks was confirmed in five groups of meat-type chickens [11] and in F1 progenies derived from crosses between a broiler line and Fayoumi or MHC-congenic lines $[55,56]$.

Since human Salmonella infection is mainly due to the consumption of eggs or meat from adult chickens, commercial egg-type chickens intravenously infected with $S$. Enteritidis have also been studied but at 13 weeks instead of at a young age [7]. Similarly, it has been demonstrated that a marker closely linked to SLC11A1 displayed a within-sire effect on liver and spleen load assessed early (three days post-infection), which confirms the possible 
Table 2: Physical and genetic positions of published loci for resistance to Salmonella in fowl.

\begin{tabular}{|c|c|c|c|c|c|c|}
\hline Chr' ${ }^{1}$ & Locus type $^{2}$ & Locus name & Trait $^{3}$ & Position ${ }^{4} \mathrm{cM}$ & Mb & Ref \\
\hline \multirow[t]{7}{*}{1} & MSAT & ADL0160 & ABR to SE vaccine & 33 & 5.93 & [15] \\
\hline & QTL & - & CSWB counts (SE) & 85 & 33.57 & [14] \\
\hline & QTL & - & CSWB counts (ST) & 207 & 68.52 & [14] \\
\hline & MSAT & ADL0020 & $\begin{array}{l}\text { ABR to SE vaccine } \\
\text { Splenic and caecal loads (SE) }\end{array}$ & 286 & 94.16 & $\begin{array}{l}{[12]} \\
{[78]}\end{array}$ \\
\hline & CG & $C D 28$ & Caecal load; ABR to SE vaccine & - & 113.90 & [62] \\
\hline & MSAT & ADL0198 & $\begin{array}{l}\text { ABR to SE vaccine } \\
\text { Splenic and caecal load (SE) }\end{array}$ & 458 & 171.74 & $\begin{array}{l}{[12]} \\
{[78]}\end{array}$ \\
\hline & CG & $I A P 1$ & $\begin{array}{l}\text { caecal load (SE) } \\
\text { Splenic load (SE) }\end{array}$ & - & 186.92 & $\begin{array}{l}{[11]} \\
{[55]}\end{array}$ \\
\hline \multirow[t]{3}{*}{2} & QTL & - & CSWB counts (SE) & 87 & 26.93 & [14] \\
\hline & CG & $M D-2$ & Splenic load (SE) & - & 122.83 & [62] \\
\hline & MSAT & MCW0051 & $A B R$ to $S E$ vaccine & 358 & 129.15 & [15] \\
\hline \multirow[t]{10}{*}{3} & MSAT & MCW0083 & ABR to $S E$ vaccine & 51 & 13.99 & [15] \\
\hline & MSAT & MCW0024 & $A B R$ to $S E$ vaccine & 237 & - & [15] \\
\hline & CG & $T G F-\beta 4$ & Caecal load (SE) & - & 18.29 & [11] \\
\hline & CG & $T G F-\beta 2$ & $\begin{array}{l}\text { Caecal load (SE) } \\
\text { ABR to SE }\end{array}$ & - & 20.54 & $\begin{array}{l}{[11]} \\
{[66]}\end{array}$ \\
\hline & CG & Gal13 & Caecal load (SE) & - & 110.20 & [60] \\
\hline & CG & Gal12 & Caecal load (SE) & - & 110.21 & [60] \\
\hline & CG & Gal11 & Caecal load (SE) & - & 110.21 & [60] \\
\hline & CG & Gal7 & $A B R$ to $S E$ vaccine & - & 110.25 & [64] \\
\hline & CG & Gal3 & $\begin{array}{l}\text { ABR to SE vaccine } \\
\text { Caecal load (SE) }\end{array}$ & - & 110.26 & $\begin{array}{l}{[60]} \\
{[64]}\end{array}$ \\
\hline & CG & Gal5 & Spleen load (SE) & - & 110.27 & [60] \\
\hline 4 & CG & TRAIL & Spleen and caecal load (SE) & - & 9.67 & [63] \\
\hline & CG & IL-2 & Caecal load (SE) & - & 55.26 & [11] \\
\hline
\end{tabular}


Table 2: Physical and genetic positions of published loci for resistance to Salmonella in fowl. (Continued)

\begin{tabular}{|c|c|c|c|c|c|c|}
\hline 5 & QTL & - & CSWB counts (ST) & 100 & 36.10 & [14] \\
\hline & QTL & - & CSWB counts (SE) & 111 & 39.28 & [14] \\
\hline & QTL & SAL1 & Splenic load (ST) & 157 & 53.24 & [13] \\
\hline & QTL & SAL1 & Splenic load (ST) & - & $\begin{array}{l}54.00- \\
54.80\end{array}$ & [74] \\
\hline & MSAT & ADL0298 & $\begin{array}{l}\text { ABR to SE vaccine } \\
\text { Splenic and caecal load (SE) }\end{array}$ & 198 & 60.23 & $\begin{array}{l}{[12]} \\
{[78]}\end{array}$ \\
\hline & CG & $T G F-\beta 3$ & Caecal load (SE) & - & 40.87 & [63] \\
\hline 6 & MSAT & ADL0138 & $\begin{array}{l}\text { ABR to SE vaccine } \\
\text { Splenic and caecal load (SE) }\end{array}$ & 56 & 10.09 & $\begin{array}{l}{[12]} \\
{[78]}\end{array}$ \\
\hline & CG & PSAP & Splenic and caecal loads (SE) & - & 13.02 & $\begin{array}{l}{[11]} \\
{[55]}\end{array}$ \\
\hline 7 & CG & SLC11A1 & $\begin{array}{l}\text { Survival rate (ST) } \\
\text { Splenic and liver loads (SE) } \\
\text { Splenic load (SE) } \\
\text { Splenic load (SE); number of } \\
\text { contaminated organs } \\
\text { Splenic load (SE); ABR to SE } \\
\text { vaccine } \\
\text { Caecal load (SE) }\end{array}$ & 80 & 23.91 & $\begin{array}{l}{[10]} \\
{[7]} \\
{[55]} \\
{[9]} \\
{[61]} \\
{[79]}\end{array}$ \\
\hline 8 & MSAT & ADL301 & ABR to $S E$ vaccine & $80 \mathrm{EL}$ & 25.10 & [15] \\
\hline 11 & QTL & - & Caecal load (SE); CSWB counts & 18 & 3.66 & [14] \\
\hline 15 & CG & $I G L$ & $\begin{array}{l}\text { Caecal load } \\
\text { ABR to SE vaccine }\end{array}$ & - & 8.17 & $\begin{array}{l}{[11]} \\
{[63]}\end{array}$ \\
\hline 16 & QTL & - & Caecal load & 2 & 0.10 & [14] \\
\hline & CG & $\mathrm{MHC1}$ & Splenic load (SE) & - & - & [55] \\
\hline & CG & $M H C$ class I a 1 domain & $A B R$ to $S E$ vaccine & - & 0.04 & [80] \\
\hline & CG & $M H C$ class I a 2 domain & $A B R$ to $S E$ vaccine & & 0.04 & [80] \\
\hline & CG & $M H C$ class I $\beta 1$ domain & $A B R$ to $S E$ vaccine & & 0.06 & [80] \\
\hline 17 & CG & TLR4 & $\begin{array}{l}\text { Survival rate (ST) } \\
\text { Survival rate (ST) } \\
\text { Number of contaminated organs }\end{array}$ & - & 4.06 & $\begin{array}{l}{[10]} \\
{[54]} \\
{[9]}\end{array}$ \\
\hline & MSAT & ADL0293 & $A B R$ to $S E$ vaccine & 26 & 6.39 & [15] \\
\hline 19 & CG & CASP1 & Caecal load & - & 0.64 & [11] \\
\hline
\end{tabular}


Table 2: Physical and genetic positions of published loci for resistance to Salmonella in fowl. (Continued)

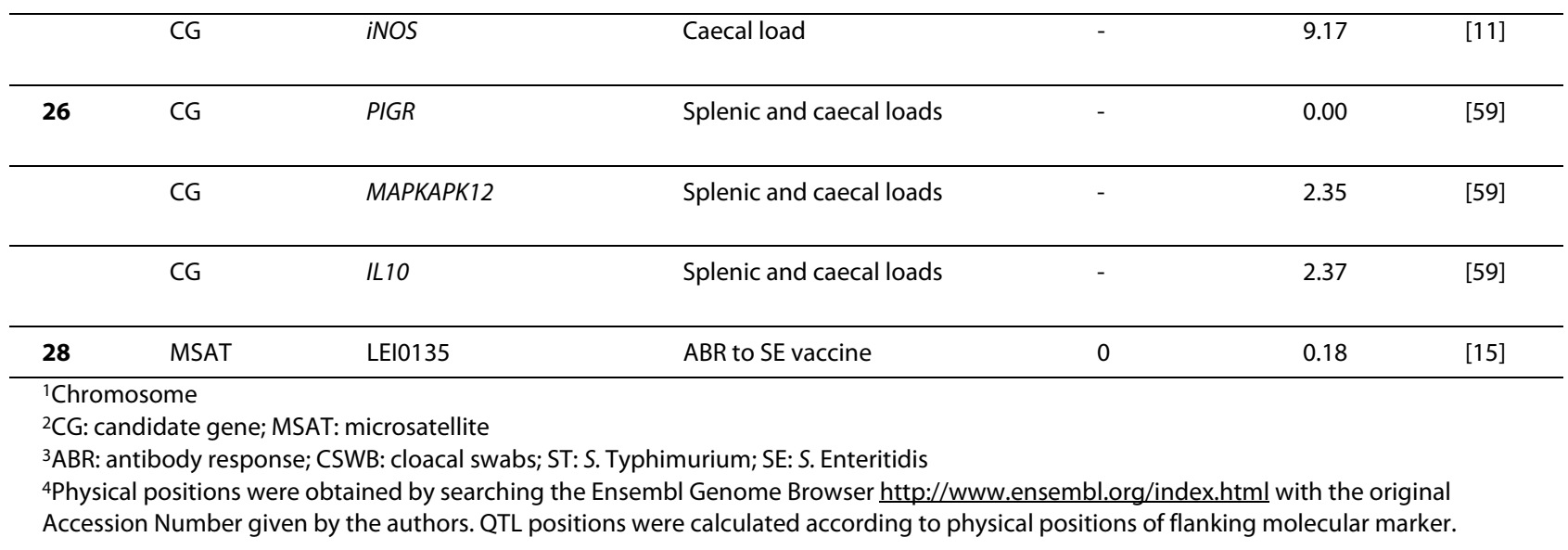

involvement of SLC11A1 early in the process of systemic infection in these chicken lines, although infection occurred at an older age. Following bacterial contamination several weeks after infection is the only way of studying the Salmonella carrier-state. Thus, the potential role of SLC11A1 in later stages of the infection was demonstrated, firstly in mice inoculated with $S$. Enteritidis at 810 weeks with spleen bacterial counts, 42 days post-infection [57]. Interestingly, it seems that different SLC11A1 alleles were involved in early vs. late resistance. The same allele may be involved both in resistance to colonisation in early stages of the infection and in a high excretion rate in later stages. Similarly, an effect of SLC11A1 on spleen contamination was then demonstrated in chicken lines orally inoculated at peak of lay and slaughtered four weeks later [9], while in the same study the role of TLR4, although suspected, was not confirmed. More recently, the effect of the SLC11A1 locus was found significantly associated with carrier-state resistance variations in divergent chick lines [58].

In addition to these two genes, many genes related to immune response in chicken have been tested for their association with caecal or splenic load after $S$. Enteritidis challenge of one-day- to three-week-old chicks (Table 2; $[11,54,55,59-63])$. Other studies have focused on the antibody response to $S$. Enteritidis vaccination [62-66]. These studies exploit either polymorphisms found in the gene itself (mainly SNP) or closely associated genetic markers. Most of these genes have been tested in progenies derived from crosses between White Leghorn MHC-congenic inbred lines and inbred Fayoumi lines. Such crosses between genetically distant parental lines are an efficient way of maximising genetic variation. However, genes identified in this way may be fixed in other populations, so that their interest for selection purposes needs to be validated.

Many genes have been identified in gene expression studies. Most of them are probably not directly responsi- ble for the actual genetic variation between these lines, but they remain functional candidates until they are tested for their role in genetic variation. Genome-wide microarray studies have led to the identification of genes differentially expressed between different chicken lines infected with $S$. Enteritidis [33-35,67] or before/after infection with $S$. Enteritidis $[31,38,68]$. Other genes have been more specifically studied, such as for instance genes coding for cytokines [69,70], Toll-like receptors $[37,71,72]$ or innate immune response genes [39].

\section{QTL analyses}

Targeted candidate gene analyses have very rarely led to the complete unravelling of the heritable part of phenotypic variations. On the contrary, QTL analyses are designed to encompass the greatest part possible of the observed variability, with the inconvenience that the genomic regions identified are anonymous and often contain several hundred genes. Until now, few QTL studies have been carried out to identify genes for acute resistance or resistance to carrier-state in chicken (Table 1). The first QTL study of Salmonella resistance analysed data from a back-cross progeny produced from White Leghorn inbred lines $\left(\left(6_{1} \times 15 \mathrm{I}\right) \times 15 \mathrm{I}\right)$ and infected at two weeks of age with $S$. Typhimurium [13]. A major QTL controlling spleen bacterial load was identified on chromosome 5 and named SAL1. SAL1 was shown to be involved in bacterial clearance by macrophages [73]. Using a $6^{\text {th }}$ generation backcross mapping population and high density SNP panels, the SAL1 locus was confirmed and its localisation was refined at a position between 54.0 and $54.8 \mathrm{Mb}$ on the long arm of chromosome 5 [74]. This region spans 14 genes, including two very striking functional candidates: CD27-binding protein (Siva) and the RAC-alpha serine/threonine protein kinase homolog, AKT1 (protein kinase B, PKB). AKT1 is involved in cellular survival pathways, primarily by inhibiting apoptotic processes. Survival factors can suppress apoptosis in a 
transcription-independent manner by activating AKT1, which then phosphorylates and inactivates components of the apoptotic machinery. AKT1 can also activate NF$\kappa B$ by regulating IкB kinase (IKK), resulting in transcription of pro-survival genes and stimulation of pro-inflammatory responses [75]. Hijacking of this pathway by the Salmonella effector protein SopB provides support for $A K T$ as a plausible candidate gene for bacterial proliferation and its association with the susceptibility/resistance status of the host.

QTL for carrier-state resistance have been identified in one back-cross and one F2 progeny, both derived from the White Leghorn inbred lines $6_{1}$ and $N$, infected at one week post-infection with either $S$. Typhiumurium (BC) or $S$. Enteritidis (F2) and assessed for their caecal and caecal lumen content bacterial loads two to six weeks later [14]. One genome-wise significant QTL on chromosome 2 and five chromosome-wise significant QTL on chromosomes 1, 5, 11 and 16 were identified (Table 2; Figure 1). Some QTL were specific to one of the two progenies studied (BC vs. F2), which can be attributed to differences in the progeny types, the serotypes used for infection, or the times of infection and phenotypic assessments. Different QTL were found for the caecal bacterial load and the caecal lumen bacterial load. Two of these QTL, on chromosomes 2 and 16, have recently been confirmed in a more targeted analysis of the same progeny [58]. Interestingly, two QTL on chromosomes 1 and 16 were validated in a completely different genetic background, i.e. lines derived from commercial chicken lines [58]. Thus, genetic studies conducted on experimental lines can be of potential interest for marker-assisted selection in commercial lines. Furthermore, two different sets of QTL and candidate genes have been confirmed in adult chickens and in chicks derived from the same commercial line, which strengthens the hypothesis of a genetic control of Salmonella carrier-state differing according to chicken's age previously formulated [16].

Other studies have more specifically focused on the antibody response to $S$. Enteritidis vaccination. Associations were found between microsatellite markers and traits related to the antibody response to $S$. Enteritidis vaccination, from data obtained respectively from $B C$ and F2 progenies derived from inbred lines selected for high/ low antibody response and from $\mathrm{F} 1$ families derived from crosses between a broiler and either MHC-congenic White Leghorn lines or the Fayoumi line [15,12]. Nevertheless, the significant microsatellites identified were not located in the same genomic regions. This could be due to genetic differences between the parental lines studied, but also to differences in the experimental conditions (Table 1). The time of assessment and possibly the vaccine used were different and may have influenced the outcome of infection.

\section{Genomic organisation of Salmonella resistance loci}

The different candidate genes, QTL and microsatellites significantly linked to Salmonella resistance are shown in Figure 1. These loci are located on 16 of the 38 autosomal chromosomes of the chicken genome. Microchromosomes are poorly represented, due to the lack of genetic markers and genome sequences in these regions. Genomic co-localisations reveal a possible common genetic background explaining variations for resistance under different experimental conditions. Genetic or physical co-localisations indicate the possibility of the colocalised loci being identical, although the possibility of close physical linkage between adjacent genes should obviously never be discarded. Three types of genetic colocalisations can be observed between the candidate genes and the Salmonella resistance QTL mentioned above. First, several co-localisations occur between QTL for antibody response-related traits [15] and candidate immune-response genes: two on chromosome 1 , one on chromosome 3, and one on chromosome 6 . Before the immunity-related genes can be considered as relevant candidates for the co-localising QTL, ideally they should be tested in the same conditions as the QTL with which they co-localise, i.e. in particular with the same phenotypic trait, in the same or similar progeny, using the same Salmonella serotype under the same infection or vaccination model. The absence of other potentially relevant candidates should also be verified in the QTL confidence intervals. Secondly, a cluster can be observed on chromosome 5, including two QTL for resistance to $S$. Enteritidis and $S$. Typhimurium [14], one QTL for the antibody response to $S$. Enteritidis vaccination [12], the QTL SAL1 and the TGF- $\beta 3$ gene. It is theoretically possible that all these QTL are actually the same gene, although the refined SAL1 locus does not include TGF- $\beta 3$ [74]. The molecular cloning of $S A L 1$, which is so far the QTL with the most important effect identified, would solve this question. Finally, a co-localisation involves the MHC on micro-chromosome 16 and a $S$. Enteritidis carrier-state QTL [14]. Due to the high density of immunity-related genes and to the poor recombination rate observed on this chromosome, identifying which gene is the causal gene at this QTL will not be easy.

\section{Conclusion}

Several candidate genes and QTL have been successfully identified as having roles in phenotypic variations related to Salmonella resistance. Despite the many differences in infection models and genetic materials used and in traits assessed, which make the comparison of these loci somewhat speculative, great progress has been achieved in the last few years to understand the genetic control of resistance to Salmonella. The diverse experimental conditions used lead to a complex sum of results, but allow a more 


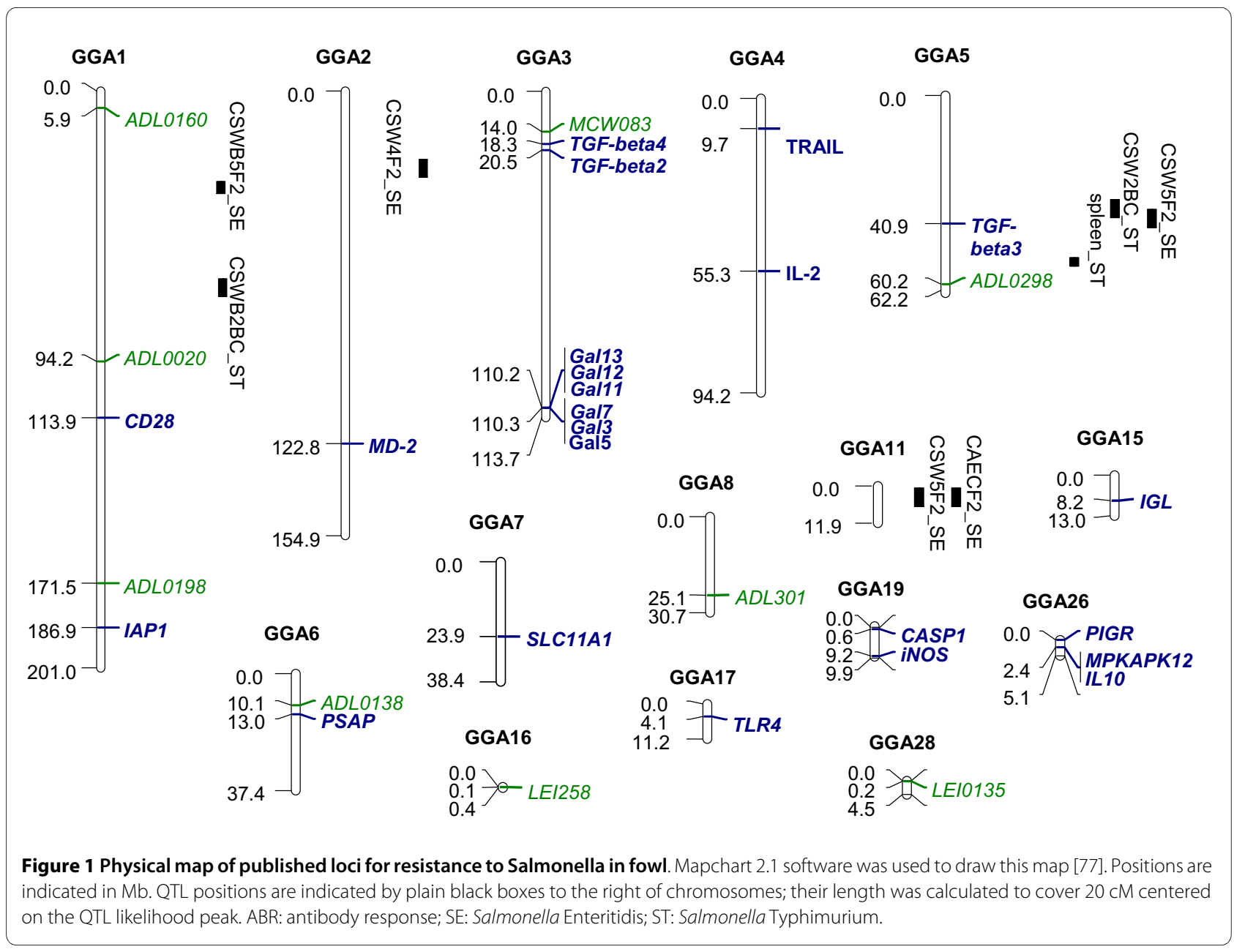

complete description of the disease. Resistance to salmonellosis and Salmonella carrier state varies according to the chicken line under study, the chicken's age, and the trait assessed, and probably many other parameters which have not been studied yet. Comparisons of the different models used raise many questions. In particular, the genetic differences between acute and carrier-state resistance and the influence of the chicken's age on resistance are interesting theoretical issues which still need to be investigated thoroughly before selection is considered. The genomic regions carrying the candidate genes TLR4 and SLC11A1, the Major Histocompatibility Complex (MHC) and the QTL SAL1, identified using several infection models, are interesting candidates for more in-depth studies.

With the development of high-throughput technologies such as microarray expression analyses and RNA-seq [76], new-generation sequencing (NGS) technologies and high density SNP genotyping, a huge quantity of differentially expressed candidate genes and polymorphisms is already available, which should speed up the unravelling of the Salmonella resistance genetic mechanisms. The most limiting factors are and will clearly remain the fre- quent and inevitable lack of precision and reliability of phenotypic assessments and the poor density of genetic recombinations in the progenies under study, which both limit the precision of QTL localisation and fine-mapping. Another limiting step resides in the choice of the relevant differentially expressed genes to be tested for their involvement in genetic variation.

All these studies will no doubt lead to a large number of genes or genome regions involved in Salmonella resistance variation and extend our theoretical knowledge of the genetic control of this disease. However, for practical applications, i.e. to implement marker assisted selection in commercial populations, it will be important to identify which of these genes are the most important. The answer will vary according to the chicken population under study and the selection criteria used, which clearly is an obstacle to practical application. Genomic selection may soon settle this matter by the direct selection of resistance-related traits in populations under selection.

This new knowledge of the genetic architecture of Salmonella resistance in fowl, in addition to genomic selection, could soon lead to the selection of more resistant animals. Combined with other measures, it should con- 
tribute in reducing the spread of the disease in commercial flocks.

\section{List of abbreviations used}

MAS: Marker Assisted Selection; MHC: Major Histocompatibility Complex; QTL: Quantitative Trait Locus; SNP: Single Nucleotide Polymorphism.

\section{Competing interests}

The authors declare that they have no competing interests.

\section{Authors' contributions}

FC wrote the manuscript. PK contributed to the chapters related to candidate genes and genomic approaches. AV contributed to the chapters related to genomics approaches and QTL detection. CB contributed to the chapters related to genetic selection and infection models. All authors read and approved the final manuscript

\section{Author Details}

IINRA, UR83 Unité de Recherches Avicoles (URA), 37380 Nouzilly, France, IInstitute for Animal Health, Compton, Berkshire RG20 7NN, UK, ${ }^{3}$ INRA, UMR0444 Laboratoire de Génétique Cellulaire (LGC), 31326 Auzeville, France and ${ }^{4}$ Roslin Institute and R(D)SVS, University of Edinburgh, Midlothian EH25 9RG, UK

Received: 21 September 2009 Accepted: 29 April 2010 Published: 29 April 2010

\section{References}

1. Brenner F, Villar R, Angulo F, Tauxe R, Swaminathan B: Salmonella nomenclature. J Clin Microbiol 2000, 38:2465-2467.

2. Bouvet P, Fougerat I, Guesnier F, Guibert F, K'ouas G, Lenormand P, Metz L, Ruckly C, Grimont P: Human salmonellosis surveillance in France: recent data from the national referee center. International Symposium on Salmonella and Salmonellosis; Ploufragran, France 2002:411-416.

3. Prévost K, Magal P, Protais J, Beaumont C: Effect of genetic resistance of the hen to Salmonella carrier-state on incidence of bacterial contamination: synergy with vaccination. Vet Res 2008, 39:20

4. Lambert W, Knox C: The inheritance of resistance to fowl typhoid in chickens. lowa State J Sci 1928, 2:179-187.

5. Roberts $E_{1}$ Card L: Inheritance of resistance to bacterial infection in animals. Illinois Agric Exper Sta Bull 1935, 419:467-493.

6. Berthelot F, Beaumont C, Mompart F, Girard-Santosuosso O, Pardon P, Duchet-Suchaux M: Estimated heritability of the resistance to cecal carrier state of salmonella enteritidis in chickens. Poult Sci 1998, 77:797-801.

7. Girard-Santosuosso O, Lantier F, Lantier I, Bumstead N, Elsen J-M Beaumont C: Heritability of susceptibility to Salmonella enteritidis infection in fowls and test of the role of the chromosome carrying the NRAMP1 gene. Genet Sel Evol 2002, 342:211-219.

8. Beaumont C, Protais J, Guillot J, Colin P, Proux K, Millet N, Pardon P. Genetic resistance to mortality of day-old chicks and carrier-sate of hens after inoculation with Salmonella enteritidis. Avian Pathol 1999, 28:131-135.

9. Beaumont C, Protais J, Pitel F, Leveque G, Malo D, Lantier F, Plisson-Petit F, Colin P, Protais M, Roy PL, Elsen JM, Milan D, Lantier I, Neau A, Salvat G, Vignal A: Effects of two candidate genes on the Salmonella carrier-state in fowl. Poult Sci 2003, 82:721-726.

10. Hu J, Bumstead N, Barrow P, Sebastiani G, Olien L, Morgan K, D M: Resistance to salmonellosis in the chicken is linked to NRAMP1 and TNC. Genome Res 1997, 7:693-704

11. Kramer J, Malek M, Lamont S: Association of twelve candidate gene polymorphisms and response to challenge with Salmonella enteritidis in poultry. Anim Genet 2003, 34:339-348.

12. Kaiser M, Deeb N, Lamont S: Microsatellite markers linked to Salmonella enterica serovar Enteritidis vaccine response in young $\mathrm{F} 1$ broiler-cross chicks. Poult Sci 2002, 81:193-201.

13. Mariani $P$, Barrow $P$, Chang H, Groenen M, Negrini R, Bumstead N: Localization to chicken chromosome 5 of a novel locus determining salmonellosis resistance. Immunogenetics 2001, 53:786-791.
14. Tilquin $P$, Barrow $P$, Marly J, Pitel F, Plisson-Petit F, Velge $P$, Vignal $A$, Baret $P$, Bumstead N, Beaumont C: A genome scan for quantitative trait loci affecting the Salmonella carrier-state in the chicken. Genet Sel Evol 2005, 37:539-561.

15. Yunis R, Heller E, Hillel J, Cahaner A: Microsatellite markers associated with quantitative trait loci controlling antibody response to Escherichia coli and Salmonella enteritidis in young broilers. Anim Genet 2002 33:407-414

16. Beaumont $C$, Chapuis $H$, Protais J, Sellier N, Menanteau P, Fravalo $P$, Velge $P:$ Resistance to Salmonella carrier state: selection may be efficient but response depends on animal's age. Genet Res 2009, 91:161-169.

17. DeVolt H, Quigley G, Byerly T: Studies of resistance to pullorum diseases in chickens. Poult Sci 1941, 20:339-341.

18. Hutt F, Crawford R: On breeding chicks resistant to pullorum disease without exposure thereto. Canad J Genet Cytol 1960, 2:357-370.

19. Hutt F, Scholes J: XIII. Breed differences in susceptibility to Salmonella pullorum. Poult Sci 1941, 20:342-352.

20. Prince W, Garren H: An investigation of the resistance of white leghorn chicks to Salmonella gallinarum. Poult Sci 1966, 45:1149-1153.

21. Smith $\mathrm{H}$ : The susceptibility of different breeds of chickens to experimental Salmonella gallinarum infection. Poultry Sci 1956, 35:701-705.

22. Bumstead N, Barrow P: Genetics of resistance to Salmonella typhimurium in newly hatched chicks. Br Poult Sci 1988, 29:521-529.

23. Bumstead N, Barrow P: Resistance to Salmonella gallinarum, S. pullorum and S. enteritidis in inbred lines of chickens. Avian Dis 1993, 37:189-193.

24. Bumstead N, Millard B, Barrow P, Cook J: Genetic basis of disease resistance in chickens. In Breeding for disease resistance in farm animals Edited by: Owen J. Axford R: CAB International; 1991.

25. Guillot J, Beaumont C, Bellatif F, Mouline C, Lantier F, Colin P, Protais J: Comparison of resistance of various poultry lines to infection by Salmonella enteritidis. Vet Res 1995, 26:81-86.

26. Duchet-Suchaux M, Léchopier P, Marly J, Bernardet P, Delaunay R, Pardon $P$ : Quantification of experimental Salmonella enteritidis carrier state in B13 leghorn chicks. Avian Dis 1995, 39:796-803.

27. Duchet-Suchaux M, Mompart F, Berthelot F, Beaumont C, Léchopier P, Pardon P: Differences in frequency, level and duration of cecal carriage between four outbred chicken lines infected orally with Salmonella enteritidis. Avian Dis 1997, 41:559-567

28. Protais J, Colin P, Beaumont C, Guillot J, Lantier F, Pardon P, Bennejean G: Line differences in resistance to Salmonella enteritidis PT4 infection. $\mathrm{Br}$ Poult Sci 1996, 37:329-339.

29. Lindell K, Saeed A, McCabe G: Evaluation of resistance of four strains of commercial laying hens to experimental infection with Salmonella enteritidis phage type eight. Poult Sci 1994, 73:757-762.

30. Kramer J, Visscher A, Wagenaar J, Boonstra-Blom A, Jeurissen S: Characterization of the innate and adaptive immunity to Salmonella enteritidis PT1 infection in four broiler lines. Veterinary Immunoland Immunopathol 2001, 79:219-233.

31. van Hemert S, Hoekman A, Smits M, Rebel J: Immunological and gene expression reponses to a Salmonella infection in the chicken intestine. Vet Res 2007, 38:51-63.

32. Vaughn $L$, Holt $P$, Moore $R$, Gast $R$, Anderson K: Crop immune response post-Salmonella Enteritidis challenge in eight commercial egg-layer strains and specific-pathogen-free White Leghorn chickens. Avian Dis 2009, 52:79-87.

33. van Hemert S, Hoekman A, Smits M, Rebel J: Gene expression responses to a Salmonella infection in the chicken intestine differ between lines. Vet Immunol Immunopathol 2006, 114:247-258.

34. Chiang H, Swaggerty C, Kogut M, Dowd S, Li X, Pevzner I, Zhou H: Gene expression profiling in chicken heterophils with Salmonella enteritidis stimulation using a chicken $44 \mathrm{~K}$ Agilent microarray. BMC Genomics 2008, 9:526.

35. Zhou H, Lamont S: Global gene expression profile after Salmonella enterica serovar enteritidis challenge in two F8 advanced intercross chicken lines. Cytogenet Genome Res 2007, 117:131-138.

36. Nerren J, Swaggerty C, Mackinnon K, Genovese K, He H, Pevzner I, Kogut $\mathrm{M}$ : Differential mRNA expression of the avian-specific toll-like recepto 15 between heterophils from Salmonella -susceptible and -resistant chickens. Immunogenetics 2009, 61:71-77.

37. Abasht B, Kaiser M, Poel J van der, Lamont S. Genetic lines differ in Tolllike receptor gene expression in spleens of chicks inoculated with Salmonella enterica serovar Enteritidis. Poult Sci 2009, 88:744-749. 
38. Cheeseman J, Kaiser M, Ciraci C, Kaiser P, Lamont S: Breed effect on early cytokine mRNA expression in spleen and cecum of chickens with and without Salmonella enteritidis infection. Dev Comp Immunol 2007 31:52-60.

39. Sadeyen J-R, Trotereau J, Protais J, Beaumont C, Sellier N, Salvat G, Velge P, Lalmanach A-C: Salmonella carrier-state in hens: study of host resistance by a gene expression approach. Microbes Infect 2006, 8:1308-1314.

40. Swaggerty C, Kogut M, Ferro P, Rothwell L, Pevzner I, Kaiser P: Differential cytokine mRNA expression in heterophils isolated from Salmonella resistant and -susceptible chickens. Immunology 2004, 113:139-148.

41. Sadeyen J-R, Trotereau J, Velge P, Marly J, Beaumont C, Barrow P, Bumstead N, Lalmanach A-C: Salmonella carrier state in chicken: comparison of expression of immune response genes between susceptible and resistant animals. Microbes Infect 2004, 6:1278-1286.

42. Bumstead N, Barrow P: Genetics of resistance to Salmonella typhimurium in newly hatched chicks. Br Poult Sci 1998, 29:521-529.

43. Swaggerty C, Ferro P, Pevzner I, Kogut M: Heterophils are associated with resistance to systemic Salmonella enteritidis infections in genetically distinct chicken lines. FEMS Immunol Med Microbiol 2005, 43:149-154.

44. Swaggerty C, Pevzner I, He H, Genovese K, Nisbet D, Kaiser P, Kogut M: Selection of broilers with improved innate immune responsiveness to reduce on-farm infection by foodborne pathogens. Foodborne Pathog Disease 2009, 6:777-783.

45. Swaggerty C, Pevzner I, Lowry V, Farnell M, Kogut M: Functional comparison of heterophils isolated from commercial broiler chickens. Avian pathol 2003, 32:95-102.

46. Kaiser M, Wing T, Lamont S: Effects of genetics, vaccine dosage, and postvaccination sampling interval on early antibody response to Salmonella enteritidis vaccine in broiler breeder chicks. Poult Sci 1998, 77:271-275

47. Kaiser MG, Lakshmanan N, Wing T, Lamont SJ: Salmonella enterica serovar Enteritidis burden in broiler breeder chicks genetically associated with vaccine antibody response. Avian Dis 2002, 46:25-31.

48. Bolder N, Janss L, Putirulan F, Wagenaar J: Resistance of broiler outbred lines to infection with Salmonella enteritidis. Avian Pathol 2002 , 31:581-587.

49. Roy M-F, Malo D: Genetic regulation of host responses to Salmonella infection in mice. Genes Immun 2002, 3:381-393.

50. Vidal S, Tremblay M, Govoni G, Gauthier S, Sebastiani G, Malo D, Skamene E, Olivier M, Jothy S, Gros P: The Ity/Lsh/Bcg locus: natural resistance to infection with intracellular parasites is abrogated by disruption of the Nramp1 gene. J Exp Med 1993, 182:655-666.

51. Girard-Santosuosso O: Partial conservation of the mammalian NRAMP1 syntenic group on chicken chromosome 7. Mamm Genome 1997, 8:614-616.

52. Hu J, Bumstead N, Burke D, FA PdL, Skamene E, Gros P, Malo D: Genetic and physical mapping of the natural resistance-associated macrophage protein 1 (NRAMP1) in chicken. Mamm Genome 1995, 6:809-815.

53. Hu J, Bumstead N, Skamene E, Gros P, Malo D: Structural organization, sequence, and expression of the chicken NRAMP1 gene encoding the natural resistance-associated macrophage protein 1. DNA Cell Biol 1996, 15:113-123.

54. Leveque G, Forgetta V, Morroll S, Smith A, Bumstead N, Barrow P, LoredoOsti J, Morgan K, Malo D: Allelic variation in TLR4 is linked to susceptibility to Salmonella enterica serovar Typhimurium infection in chickens. Infect Imm 2003, 71:1116-1124.

55. Lamont S, Kaiser M, Liu W: Candidate genes for resistance to Salmonella enteritidis colonization in chickens as detected in a novel genetic cross. Vet Immunol Immunopathol 2002, 87:423-428.

56. Liu W, Miller M, Lamont S: Association of MHC class I and class II gene polymorphisms with vaccine or challenge response to Salmonella enteritidis in young chicks. Immunogenetics 2002, 54:582-590.

57. Caron J, Loredo-Osti J, Laroche L, Skamene E, Morgan K, Malo D: Identification of genetic loci controlling bacterial clearance in experimental Salmonella enteritidis infection: an unexpected role of Nramp1 (Slc11a1) in the persistence of infection in mice. Genes Immun 2002:196-204

58. Calenge F, Lecerf F, Demars J, Feve K, Vignoles F, Pitel F, Vignal A, Velge $P$ Sellier N, Beaumont C: QTL for resistance to Salmonella carrier state confirmed in both experimental and commercial chicken lines. Anim Genet 2009, 40:590-597.
59. Ghebremicael S, Hasenstein J, Lamont S: Association of interleukin-10 cluster genes and Salmonella response in the chicken. Poult Sci 2008, 87:22-26.

60. Hasenstein J, Lamont S: Chicken gallinacin gene cluster associated with Salmonella response in advanced intercross line. Avian Dis 2007 51:561-567.

61. Liu W, Kaiser M, Lamont S: Natural resistance-associated macrophage protein 1 gene polymorphisms and response to vaccine against or challenge with Salmonella enteritidis in young chicks. Poult Sci 2003 82:259-266

62. Malek M, Hasenstein J, Lamont S: Analysis of chicken TLR4, CD28, MIF, $M D-2$, and LITAF genes in a Salmonella enteritidis resource population. Poult Sci 2004, 83:544-549.

63. Malek M, Lamont S: Association of INOS, TRAIL, TGF-beta2, TGF-beta3, and IGL genes with response to Salmonella enteritidis in poultry. Genet Sel Evol 2003, 35:S99-S111.

64. Hasenstein J, Zhang G, Lamont S: Analyses of five gallinacin genes and the salmonella enterica serovar Enteritidis response in poultry. Infect Immun 2006, 74:3375-3380.

65. Zhou H, Lamont S: Associations of six candidate genes with antibody response kinetics in hens. Poul Sci 2003, 82:1118-1126.

66. Zhou $\mathrm{H}$, Lamont $\mathrm{S}$ : association of transforming growth factor beta genes with quantitative trait loci for antibody response kinetics in hens. Animal Genet 2003, 34:275-282.

67. van Hemert S, Hoekman A, Smits M, Rebel J: Early host gene expression responses to a Salmonella infection in the intestine of chickens with different genetic background examined with cDNA and oligonucleotide microarrays. Comp biochem physiol Part D Genomics Proteomics 2006, 1:292-299.

68. Zhang S, Lillehoj H, Kim C, Keeler CJ, Babu U, Zhang M: Transcriptional response of chicken macrophages to Salmonella enterica serovar Enteritidis infection. Dev Biol (Basel) 2008, 132:141-151.

69. Kaiser M, Cheeseman J, Kaiser P, Lamont S: Cytokine expression in chicken peripheral blood mononuclear cells after in vitro exposure to Salmonella enterica serovar Enteritidis. Poult Sci 2006, 85:1907-1911.

70. Redmond S, Chuammitri P, Andreasen C, Palic D, Lamont S: Chicken heterophils from commercially selected and non-selected genetic lines express cytokines differently after exposure to Salmonella enteritidis. Vet Immunol Immunopathol 2009, 132:129-134.

71. Abasht B, Kaiser M, Lamont S: Toll-like receptor gene expression in cecum and spleen of advanced intercross line chicks infected with Salmonella enterica serovar Enteritidis. Vet Immunol Immunopathol 2008, 123:314-323.

72. Mackinnon K, He H, Nerren J, Swaggerty C, Genovese K, Kogut M: Expression profile of toll-like receptors within the gastrointestinal tract of 2-day-old Salmonella enteriditis-infected broiler chickens. Vet Microbiol 2009, 137:313-319.

73. Wigley $P$, Hulme S, Bumstead N, Barrow P: In vivo and in vitro studies of genetic resistance to systemic salmonellosis in the chicken encoded by the SAL1 locus. Microbes Infect 2002, 4:1111-1120.

74. Fife M, Salmon N, Hocking P, Kaiser P: Fine mapping of the chicken salmonellosis resistance locus (SAL1). Animal Genet 2009, 40:871-877.

75. Madrid L, Wang C, Guttridge D, Schottelius A, Baldwin A, Mayo M: Akt suppresses aptoptosis by stimulating the transactivation potential of the RelA/p65 subunit of NF-kappaB. Mol Cell Biol 2000, 20:1626-1638.

76. Wang Z, Gerstein M, Snyder M: RNA-Seq: a revolutionary tool for transcriptomics. Nat Rev Genet 2009, 10:57-63.

77. Voorips R: MapChart: Software for the graphical presentation of linkage maps and QTLs. J Hered 2002, 93:77-78.

78. Kaiser MG, Lamont SF: Microsatellites linked to Salmonella enterica serovar Enteritidis burden in spleen and cecal content of young F-1 broiler-cross chicks. Poult Sci 2002, 81:657-663.

79. Kramer J, Visscher A, Wagenaar J, Cornelissen J, Jeurissen S: Comparison of natural resistance in seven genetic groups of meat-type chicken. $\mathrm{Br}$ Poult Sci 2003, 44:577-585.

80. Zhou H, Lamont S: Chicken MHC class I and II gene effects on antibody response kinetics in adult chickens. Immunogenetics 2003, 55:133-140.

doi: $10.1186 / 1297-9686-42-11$

Cite this article as: Calenge et al., Genetic control of resistance to salmonellosis and to Salmonella carrier-state in fowl: a review Genetics Selection Evolution 2010, 42:11 